\title{
Clinical characteristics and surgical outcomes of solitary spinal epidural cavernous angiomas
}

\author{
TAO YANG ${ }^{1,2}$, FEI WANG ${ }^{1,2}$ and CHAOSHI NIU ${ }^{1,2}$ \\ ${ }^{1}$ Department of Neurosurgery, The First Affiliated Hospital of University of Science and Technology of China; \\ ${ }^{2}$ Department of Neurosurgery, Anhui Province Hospital, Hefei, Anhui 230001, P.R. China
}

Received September 9, 2017; Accepted January 11, 2018

DOI: $10.3892 / \mathrm{ol} .2018 .8024$

\begin{abstract}
The majority of spinal cavernous angiomas (CAs) originate from the vertebral bodies with or without epidural space extension. Solitary epidural CAs are rare. In the present study, we retrospectively reviewed the records of 12 patients who underwent microsurgery for solitary spinal epidural CAs. All patients had performed pre- and postoperative magnetic resonance imaging. The patients were 7 females and 5 males with the mean age of 52.1 years. Two tumors were located in the cervicothoracic spine, nine in the thoracic spine and one in the lumbar spine, respectively. Solitary epidural CAs generally exhibited isointensity on T1-weighted images and hyperintesity on T2-weighted images. Contrast-enhanced T1-weighted images showed homogeneous markedly enhancement. Gross total resection (GTR) was achieved in 11 cases, and subtotal resection (STR) was achieved in 1 case. During an average follow up of 35.9 months, neurological function was improved in 11 patients and in one patient, preoperative status was maintained. No patient experienced tumor recurrence. These findings suggest that CAs should be considered in the differential diagnosis of spinal epidural lesions. Early surgery is advocated to prevent irreversible neurological deficits. When aggravated by a large amount of acute hemorrhage, neurological deterioration is usually acute and prompt surgical decompression is the optimal choice. Because of the excessive vascularity of CAs, en bloc resection is recommended. In addition, a good clinical outcome after GTR can be expected, and the risk of long-term recurrence is low.
\end{abstract}

\section{Introduction}

Cavernous angioma (CA) is an uncommon benign vascular malformation, consisting of dilated thin-walled sinusoidal

Correspondence to: Dr Chaoshi Niu, Department of Neurosurgery, The First Affiliated Hospital of University of Science and Technology of China, 17 Lujiang Road, Hefei, Anhui 230001, P.R. China

E-mail: niuchaoshi@126.com

Key words: cavernous angiomas, spinal epidural tumors, neuroimaging, surgery, long-term outcome vascular spaces lacking intervening nervous tissue (1). These lesions are usually located in the intracranial structure (2). In the spine, CA predominantly affects the vertebral bodies with or without epidural space extension (3). Solitary epidural CAs not originating from the vertebral bone are relatively rare. With the aid of magnetic resonance imaging (MRI), solitary epidural CAs are being discovered in increasing numbers; nevertheless, most previous studies are case reports with an associated literature review and large series studies are very limited in the literature (2-17). Because of the risk of spontaneous and intraoperative bleeding, solitary epidural CAs need to get neurosurgeons more attention. In this series, we present the data of 12 patients with intraoperatively and histologically proven solitary epidural CAs from a single center. The clinical presentations, radiological features and surgical outcomes are presented and discussed.

\section{Materials and methods}

Between April 2011 to August 2017, 12 patients with solitary epidural CAs underwent microsurgery in Department of Neurosurgery, Anhui Province Hospital. A patient was included in the study based on the following criteria: i) a solitary epidural lesion present on MRI; ii) intraoperative confirmation of a solitary epidural lesion; and iii) a postoperative pathological diagnosis of CA. Clinical data were collected with institutional review board approval. Surgery was performed in all cases through posterior approach. Histological specimens were sent to the Department of Pathology for histological confirmation. Follow-up data for all patients were obtained during individual office visits or telephone interviews. Modified Japanese Orthopedic Association (JOA) scores (Table I) were applied to assess neurological function (18).

\section{Results}

Clinical presentations. The patients were 7 females and 5 males with the mean age of 52.1 years (range, 25-73 years). The mean duration of symptoms was 8.1 months (range, 12 h-2 years). The clinical course showed two patterns: A chronically progressive course $(n=10)$, and an acute onset $(n=2)$. The presentations included anesthesia (11 cases, 92.7\%), motor deficit ( 9 cases, $75 \%$ ), pain ( 3 cases, $25 \%$ ), and sphincter dysfunction (2 cases, 16.7\%). The preoperative JOA score 
was $10.5 \pm 1.75$ (range, 7-13). The detailed clinical profiles are summarized in Table II.

Radiological features. CAs were located in cervicothoracic ( 1 case, $8.3 \%$ ), thoracic ( 9 cases, $75 \%$ ), and lumbar ( 2 cases, $16.7 \%$ ) spine. The lesion was isointense in 10 cases, and hypo-and isointense in 2 cases on T1-weighted images (WI). The T2-WI revealed the lesion was hyperintense in 10 cases, iso- to hyperintense in 2 cases. No lesion was surrounded by a hypointense hemosiderin ring on T2-WI. Contrast-enhanced T1-WI revealed homogeneous markedly enhancement in 9 cases and heterogeneous markedly enhancement in 3 cases. Eight lesions were located in the dorsal spinal canal and 4 were in the lateral canal. In 6 cases, the lesion extended into the intervertebral foramen, and none had extended to the paravertebral space. Widening of intervertebral foramen was not seen in the 6 cases. According to the preoperative MRI, only one case was diagnosed as CA. The differential diagnosis included schwannomas (6 cases, 50\%), meningiomas ( 3 cases, 25\%) and epidural hemangioma ( 2 cases, 16.7\%). The detailed radiological features are summarized in Table III. An illustrative example of case 11 is illustrated in Figs. 1 and 2.

Surgical outcomes and pathological findings. After admission to the neurosurgical department, 2 patients with acute onset were treated surgically within $3 \mathrm{~h}$. All lesions were resected through the posterior approach using an operative microscope. Intraoperatively, the lesions were purple-reddish, lobulated or nodular in shape, and soft in texture. The lesions were highly vascular and easily bloody when touching. In 6 cases, the lesions extended into adjacent neural foramen and nerve roots. Most lesions were well demarcated from the dura and facilitated their exposure and dissection. Gross total resection (GTR) was achieved in 11 cases $(91.6 \%)$, and subtotal resection (STR) was achieved in one case (8.3\%). En bloc resection was performed in 7 cases ( 5 cases without intervertebralforamen extension, 2 cases with intervertebralforamen extension). Piecemeal resection was achieved in 5 cases ( 4 cases with intervertebralforamen extension, 1 case without intervertebralforamen extension). Blood loss during en bloc resection was $157.14 \pm 49.49 \mathrm{ml}$ (range, 100-200 $\mathrm{ml}$ ) and that during piecemeal resection was $380 \pm 82.46 \mathrm{ml}$ (range, 300-500 ml). The blood loss during en bloc resection was significantly less $(\mathrm{P}<0.05)$ than that in piecemeal resection group.

Histopathological examination revealed each lesion consisted of a large number of thin-walled vessels in collagenous connective tissue, lined by a single layer of endoththelial cells (Fig. 3). Some of vessels were filled with blood or thrombi.

Follow-up. After surgery immediately, 9 patients with progressive course experienced improvement, 2 patients with acute onset remained unchanged from the preoperative condition. A mild worsening of neurological deficits was seen in one patient with 2-year history of illness, but improved later to a better status than preoperatively. During a mean follow-up period of 35.9 months, neurological status had markedly improved in 11 patients and was stable in one patient compared with their preoperative neurological deficit. At the last assessment, the postoperative JOA score was $14.42 \pm 2.36$ (range, 7-16). The final JOA score was significantly improved $(\mathrm{P}<0.05)$ over the
Table I. Modified Japanese Orthopedic Association scale (18).

\begin{tabular}{|c|c|}
\hline Section & $\begin{array}{l}\text { Score } \\
\text { (points) }\end{array}$ \\
\hline \multicolumn{2}{|l|}{ Motor function of upper extremity } \\
\hline Unable to feed oneself & 0 \\
\hline $\begin{array}{l}\text { Unable to use knife and fork; able to } \\
\text { eat with a spoon }\end{array}$ & 1 \\
\hline Able to use knife and fork with much difficulty & 2 \\
\hline Able to use knife and fork with slight difficulty & 3 \\
\hline Normal & 4 \\
\hline \multicolumn{2}{|l|}{ Motor function of lower extremity } \\
\hline Unable to walk & 0 \\
\hline Can walk on flat floor with walking aid & 1 \\
\hline Can walk up and/or down stairs with handrail & 2 \\
\hline Lack of stability and smooth gait & 3 \\
\hline Normal & 4 \\
\hline \multicolumn{2}{|l|}{ Sensory function of upper extremity } \\
\hline Severe sensory loss or pain & 0 \\
\hline Mild sensory loss & 1 \\
\hline Normal & 2 \\
\hline \multicolumn{2}{|l|}{ Sensory function of lower extremity } \\
\hline Severe sensory loss or pain & 0 \\
\hline Mild sensory loss & 1 \\
\hline Normal & 2 \\
\hline \multicolumn{2}{|l|}{ Sensory function of trunk extremity } \\
\hline Severe sensory loss or pain & 0 \\
\hline Mild sensory loss & 1 \\
\hline Normal & 2 \\
\hline \multicolumn{2}{|l|}{ Bladder function } \\
\hline Unable to void & 0 \\
\hline Marked difficulty in micturition (retension) & 1 \\
\hline Difficulty in micturition (frequency, hesitation) & 2 \\
\hline Normal & 3 \\
\hline
\end{tabular}

preoperative JOA score. Postoperative MRI results showed no tumor recurrence in all cases. Surgical outcomes and assessment of neurological function are summarized in Table II.

\section{Discussion}

Spinal CAs are relatively rare, accounting for $12 \%$ of spinal vascular anomalies $(2,5)$. Solitary epidural CAs are extremely rare. Our series adds 12 cases, which is a substantial addition to the existing literature. In our group, the age ranged from 25 to 73 years, with a mean age of 52.1 years, which accorded with the literature report $(15,17)$. And besides, a mild female predilection was noted (female/male ratio of 1.4:1). Some authors suggest that reason for the female predominance of spinal CAs may be hormonal effects $(15,19)$. However, this hypothesis has not yet been proven. According to the literature on intramedullary CAs, $45 \%$ of tumors were in the cervical region, $20 \%$ were in the cervicothoracic region, and $35 \%$ were in the thoracic region (1). In our study, the most common location 


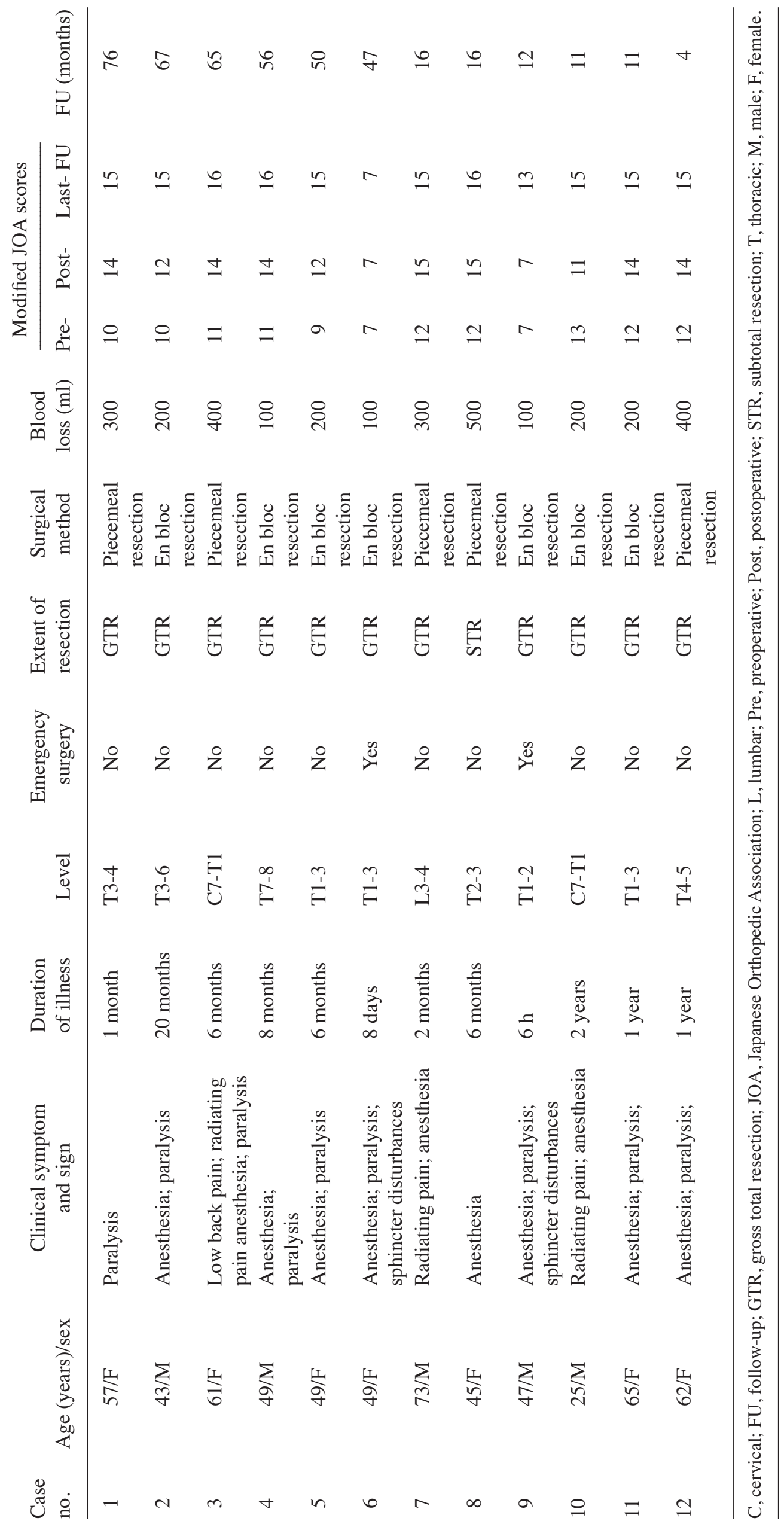


Table III. Magnetic resonance imaging of 12 patients with solitary spinal epidural cavernous angiomas.

\begin{tabular}{|c|c|c|c|c|c|c|c|}
\hline \multirow[b]{2}{*}{ Case } & \multirow[b]{2}{*}{ Position } & \multicolumn{3}{|c|}{ MRI findings } & \multirow{2}{*}{$\begin{array}{l}\text { Hypointense } \\
\text { hemosiderin } \\
\text { ring }\end{array}$} & \multirow{2}{*}{$\begin{array}{l}\text { Intervertebral } \\
\text { foramen } \\
\text { extension }\end{array}$} & \multirow{2}{*}{$\begin{array}{c}\text { Preoperative } \\
\text { diagnosis }\end{array}$} \\
\hline & & T1-WI & T2-WI & $+\mathrm{GA}$ & & & \\
\hline 1 & Left & Isointense & Hyperintense & $\begin{array}{l}\text { Heterogeneous; } \\
\text { markedly }\end{array}$ & No & Yes & Schwannoma \\
\hline 2 & Dorsal & Isointense & Hyperintense & $\begin{array}{l}\text { Homogeneous; } \\
\text { markedly }\end{array}$ & No & No & $\begin{array}{l}\text { Cavernous } \\
\text { angiomas }\end{array}$ \\
\hline 3 & Dorsal & Isointense & Hyperintense & $\begin{array}{l}\text { Homogeneous; } \\
\text { markedly }\end{array}$ & No & Yes & Schwannoma \\
\hline 4 & Dorsal & Isointense & Hyperintense & $\begin{array}{l}\text { Homogeneous; } \\
\text { markedly }\end{array}$ & No & No & Meningioma \\
\hline 5 & Dorsal & Isointense & Hyperintense & $\begin{array}{l}\text { Homogeneous; } \\
\text { markedly }\end{array}$ & No & No & Meningioma \\
\hline 6 & Dorsal & Hypo-isorintense & Hyperintense & $\begin{array}{l}\text { Heterogeneous; } \\
\text { markedly }\end{array}$ & No & No & Hematoma \\
\hline 7 & Left & Isointense & Hyperintense & $\begin{array}{l}\text { Homogeneous; } \\
\text { markedly }\end{array}$ & No & Yes & Schwannoma \\
\hline 8 & Right & Isointense & Hyperintense & $\begin{array}{l}\text { Homogeneous; } \\
\text { markedly }\end{array}$ & No & Yes & Schwannoma \\
\hline 9 & Dorsal & Hypo-isorintense & Hyperintense & $\begin{array}{l}\text { Heterogeneous; } \\
\text { markedly }\end{array}$ & No & No & Hematoma \\
\hline 10 & Right & Isointense & $\begin{array}{l}\text { Hypo- and } \\
\text { hyperintense }\end{array}$ & $\begin{array}{l}\text { Homogeneous; } \\
\text { markedly }\end{array}$ & No & Yes & Schwannoma \\
\hline 11 & Dorsal & Isointense & Hyperintense & $\begin{array}{l}\text { Homogeneous; } \\
\text { markedly }\end{array}$ & No & Yes & Schwannoma \\
\hline 12 & Dorsal & Isointense & Hyperintense & $\begin{array}{l}\text { Homogeneous; } \\
\text { markedly }\end{array}$ & No & No & Meningioma \\
\hline
\end{tabular}

+GA, gadolinium administration; MRI, magnetic resonance imaging; WI, weighted images.

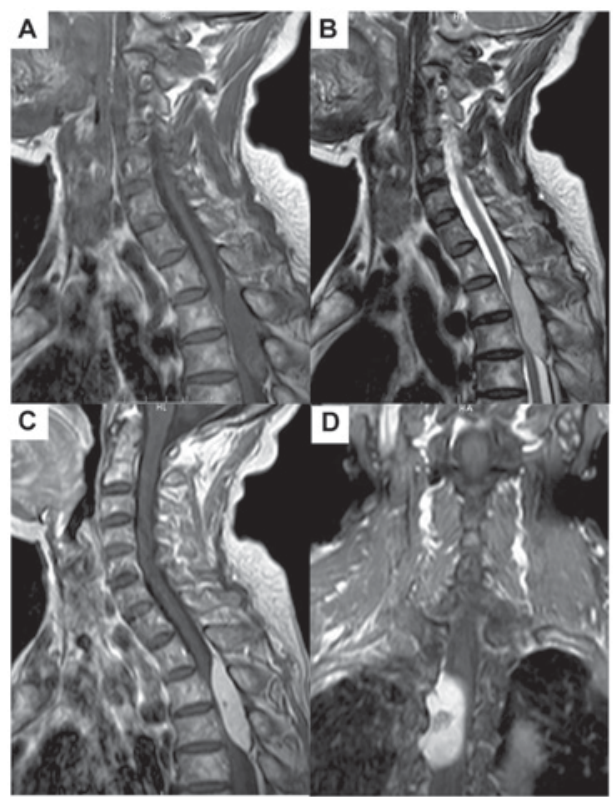

Figure 1. Case 11: Magnetic resonance imaging shows a spindle shaped epidural tumor at the T1-T3 levels. The tumor is isointense on (A) T1-weighted image (WI) and hyperintense on (B) T2-WI. (C) Contrast-enhanced T1-WI reveals homogeneous markedly enhancement and severe cord compression. (D) Coronary contrast-enhanced T1-WI exhibits the tumor is located dorsal-laterally, with extension through the intervertebral foramen.

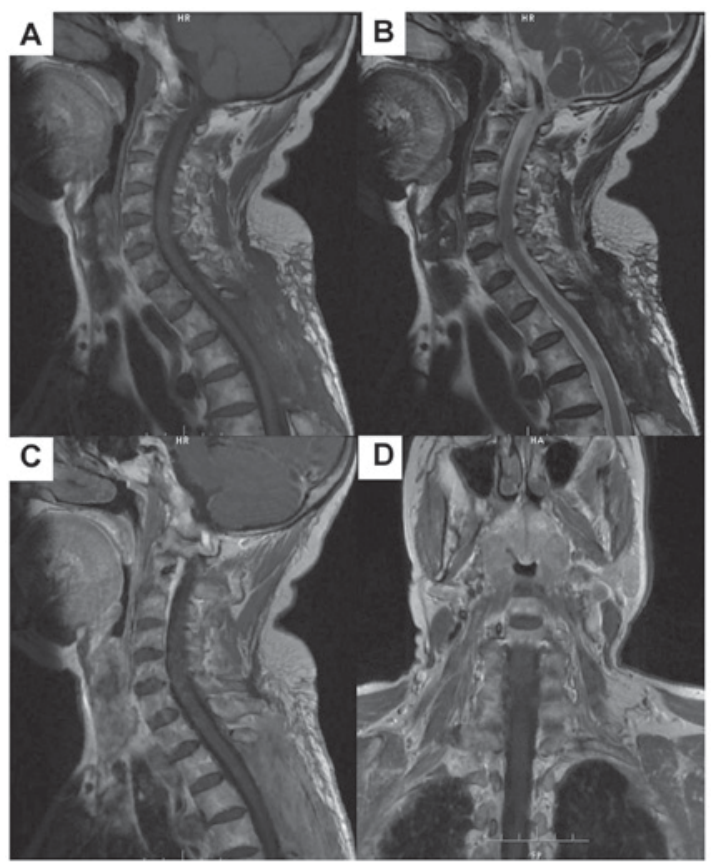

Figure 2. Ten months after surgery, magnetic resonance imaging shows no residual tumor, and the spinal cord is decompressed (A) T1-weighted image (WI), (B) T2-WI, (C) contrast-enhanced T1-WI, (D) coronary contrast-enhanced T1-WI). 

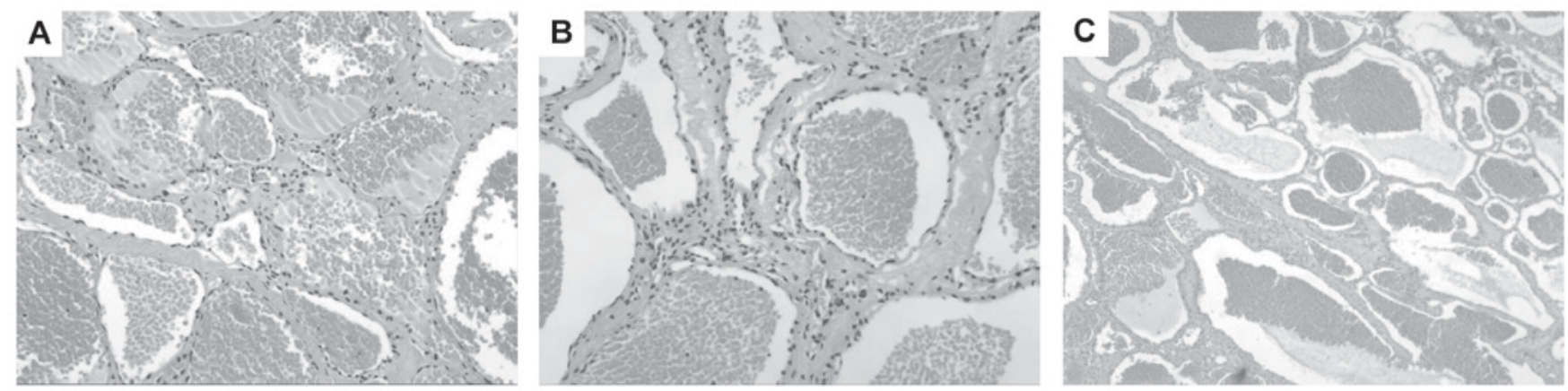

Figure 3. Photomicrographs illustrates that all lesions consisted of a large number of thin-walled vessels, which lined by a single layer of endoththelial cells and contain blood clots or thrombi. (A) case 7, (B) case 10, (C) case 11. Hematoxylin and eosin stain, original magnification, x200.

is thoracic spine in about $75 \%$ of cases, followed by lumbar region in fewer than 20\%; a cervical location is extremely rare.

The presentations of solitary epidural CAs can be classified as two patterns: a chronically progressive type (83.3\%) and an acute type $(16.7 \%)$. The chronically progressive type with progressive spinal cord or spinal nerve root compression, is usually caused by slow enlargement of the lesion, which was thought to be caused by small repeated intralesional hemorrhages and embolisms, the proliferation of blood vessels (4). In the chronically progressive type, the symptom at onset was anesthesia or radiculopathy. Motor deficit eventually appeared in the late stages. The acute type, with a sudden onset of neurological deterioration, was usually caused by a large amount of acute hemorrhage $(3,6,8)$. In this type, the initial symptom was a sudden onset of aesthesia, followed by rapid development of paralysis and sphincter disturbances. All these findings corresponded to the previous reports $(3,4,6,8)$.

The origin of solitary epidural CAs is still unknown. Caruso et al (6) postulated that the specific epidural localization may be explained by the embryological development of dura mater; the vascular elements from the primordial plexus may have some influence in the postnatal development of a cavernous lesion. This theory is attractive because it provides an easily understandable mechanism. However, CAs are not necessarily congenital, as some reports describe acquired cavernous malformation $(20,21)$. Thus, various pathogenic mechanisms may cause these lesions.

Compared with common epidural tumors, the diagnosis of solitary epidural CAs is very critical in preventing unnecessary operative bleeding. Spinal angiography has no role in diagnosis as CAs have no communication with the spinal arteries $(4,10)$. MRI is the most reliable diagnostic tool for spinal epidural CAs (5). On MRI, epidural CAs are usually creeping growth and showed lobulated-spindle shaped with taper ends, which may be due to the softer texture of the CA and the limited epidural space (14). Owing to stagnant blood and slow blood flow, they are generally isointense on T1-WI and hyperintense on T2-WI (14,22). Contrast-enhanced T1-WI shows homogeneous enhancement because of much sinusoid structure in the tumor (4); nevertheless, sometimes heterogeneous signal can also be noticed due to intralesional hemorrhage or thrombus $(10,14)$. The most striking difference in the MRI characteristics between epidural and intramedullary CAs is the lack of a ring of hypointensity from hemosiderin deposit $(9,16)$. This may be result of more rapid removal of blood products outside the blood-brain barrier (2). In our group, most of the lesions grow dorsally within the spinal canal. The larger available epidural space and the lower resistance in the posterior portion of the spinal canal may be explanations $(5,14)$. In 6 cases, the tumors grew into the intervertebral foramen, which may be due to the loose tissue structure inside the neuroforamen $(15,23)$. Solitary epidural CAs should be differentiated from epidural contrast-enhancing lesions, such as schwannomas, meningiomas, lymphomas and angiolipomas. Schwannomas always have a smooth contour, cystic changes and necrosis, extending into the paraspinal region with the enlargement of intervertebral foramen, which could be the clue to the differential diagnosis of CAs $(3,5,13,24)$. However, some reports describe intervertebral foramen widening in epidural CAs $(3,14)$, which make CAs difficult to differentiate from schwannomas. Meningiomas are rarely located in epidural space. Nevertheless, isointense signal to the spinal cord with frequent broad dural attachment (dural tail sign ) on the contrast-enhanced T1-WI favors the diagnosis of epidural meningiomas (25). Lymphomas are characterized by isointense or hyperintense signal on T2-WI, less frequent paravertebral extension and intervertebral foramen widening (13). An angiolipoma is typically hyperintense on T1-and T2-WI because of fat content, while the fat in a CA is usually absent (26).

Although solitary epidural CAs are considered to have typical imaging features, definitive preoperative diagnosis may still be challenging based only on MRI. An accurate diagnosis depends on pathology. Histologically, CAs must be distinguished from arteriovenous malformations and capillary hemangiomas $(27,28)$. The arteriovenous malformation shows with a cluster of abnormal arteries and veins and vessel walls containing elastin, and smooth muscle (28). The characteristic features of capillary hemangioma are thin irregular capillary-sized vessels caught in low attenuating fibroses, lobular architecture and the presence of a lining of a continuous basal lamina (29). Typical histological features of CAs include large number of sinusoidal channels in collagenous tissue, sometimes with thrombosis, blood, calcification, and perivascular hemosiderin deposition $(2,7,11,12)$. In the present study, all histological characteristics were consistent with CAs.

Given the tendency of hemorrhage and histologically benign, complete resection should be currently the best treatment for symptomatic epidural CAs. According to the literature, the GTR rate is $57.1-100 \%$ in solitary epidural 
CAs $(5,16)$. In our series, $91.6 \%$ of the tumors showed well-demarcated dissection plane and no tight adhesion to the dura mater, and GTR was achieved. However, diffuse dural attachment associated with intervertebral foramen extension is impossible to resect completely. Thus, STR is acceptable to improve the neurologic function to avoid severe complications (17). Because of the excessive vascularity of CAs, en bloc resection was advocated and tumor biopsy should be avoided (17). We used bipolar coagulation to disrupt the abnormal proliferation of feeding arteries and draining veins sequentially. Shrinkage of the tumor through extended of its surface avoids massive bleeding and permits safer handling of the lesion. In our study, en bloc resection was achieved in $58.3 \%$ of the patients. However, if CAs are densely adhered to attached nerve rootlets or extend beyond the intervertebral foramen, en bloc resection was difficult to achieve and piecemeal resection has to be done. Although intraoperative bleeding in piecemeal resection group was significantly more $(\mathrm{P}<0.05)$ than that in en bloc resection group, it still could be controlled by using careful microsurgical techniques such as low-power bipolar coagulation and tightly packed Gelfoam roll compression. Embolization is always useless for epidural CAs because of their slow blood flow $(4,15)$.

At the last evaluation, the JOA scores of most patients had significantly improved $(\mathrm{P}<0.05)$; moreover, no tumor recurrence was observed. Although underwent a emergency surgery, one patient with a sudden onset did not have any improvement due to delayed admission after neurological deterioration. A large amount of acute hemorrhage and spinal cord compression could cause severe neurologic damage such as sphincter dysfunction. Thus, for symptomatic patients with sudden neurological deterioration, early surgical decompression should be performed to prevent further neurological damage.

Thus far, the efficacy of radiotherapy has not been reliably evaluated since the natural history of epidural CAs is still controversial (5). In our study, the STR case did not receive radiotherapy, and had no tumor recurrence. Some authors advocate radiotherapy as an adjuvant therapy for residual tumor after STR (30), but others have thought that the procedure may be ineffective and produce radiation damage to the spinal cord (15). Recently, Sohn et al (7) suggested that image-guided stereotactic radiosurgery (SRS) enable accurate targeting of specific lesions with relatively high doses and minimal collateral risk. They determined that the equivalent hypofractionated dose of $32 \mathrm{~Gy}$ in 4 fractions would be the most appropriate and effective treatment while spinal cord irradiation (total volume, $2.4 \mathrm{~cm}^{3}$ ) was kept to less than $4 \mathrm{~Gy}$ in the partial volume of $0.7 \mathrm{~cm}^{3}(7)$. This treatment protocol delivered rapid clinical benefits and long-term tumor control in one case of spinal epidural CA in the thoracic spine (7). However, therapeutic effect of SRS for the local control of epidural CAs should be investigated further for this limited number of cases.

In conclusion, solitary epidural CAs should be considered in the differential diagnosis of a middle-aged patient with an epidural tumor involving the thoracic regions, if the lesion has dorsal localization and homogeneous enhancement on MRI. Chronically progressive spinal cord and spinal nerve root compression are main clinical symptoms. Early surgery is advocated to prevent irreversible neurological deficits.
When aggravated by a large amount of acute hemorrhage, neurological deterioration is usually acute and prompt surgical decompression is the best choice. Because of the excessive vascularity of CAs, en bloc resection is recommended and piecemeal resection should be avoided. When GTR cannot be achieved, STR of the lesions for releasing cord compression is advised, and radiological follow-up is required. In addition, a good clinical outcome after GTR can be expected, and the risk of long-term recurrence is low.

\section{Acknowledgements}

This study was supported by the National Natural Science Foundation of China (grant no. 81502141) and the Science and Technology Project grant from Anhui Province (grant no. 1606c08235).

\section{References}

1. Tong X, Deng X, Li H, Fu Z and Xu Y: Clinical presentation and surgical outcome of intramedullary spinal cord cavernous malformations. J Neurosurg Spine 16: 308-314, 2012.

2. Zevgaridis D, Büttner A, Weis S, Hamburger C and Reulen HJ: Spinal epidural cavernous hemangiomas. Report of three cases and review of the literature. J Neurosurg 88: 903-908, 1998.

3. Talacchi A, Spinnato S, Alessandrini F, Iuzzolino P and Bricolo A: Radiologic and surgical aspects of pure spinal epidural cavernous angiomas. Report on 5 cases and review of the literature. Surg Neurol 52: 198-203, 1999.

4. Aoyagi N, Kojima K and Kasai H: Review of spinal epidural cavernous hemangioma. Neurol Med Chir (Tokyo) 43: 471-475, 2003.

5. Hatiboglu MA, Iplikcioglu AC and Ozcan D: Epidural spinal cavernous hemangioma. Neurol Med Chir (Tokyo) 46: 455-458, 2006.

6. Caruso G, Galarza M, Borghesi I, Pozzati E and Vitale M: Acute presentation of spinal epidural cavernous angiomas: Case report. Neurosurgery 60: E575-E576, 2007.

7. Sohn MJ, Lee DJ, Jeon SR and Khang SK: Spinal radiosurgical treatment for thoracic epidural cavernous hemangioma presenting as radiculomyelopathy: Technical case report. Neurosurgery 64 : E1202-E1203, 2009.

8. Sarikaya-Seiwert S, Gierga K, Wessalowski R, Steiger HJ and Hänggi D: Solitary spinal epidural cavernous angiomas in children presenting with acute neurological symptoms caused by hemorrhage. J Neurosurg Pediatr 5: 89-93, 2010.

9. Floeth F, Riemenschneider M and Herdmann J: Intralesional hemorrhage and thrombosis without rupture in a pure spinal epidural cavernous angioma: A rare cause of acute lumbal radiculopathy. Eur Spine J 19 (Suppl 2): S193-S196, 2010.

10. Sanghvi D, Munshi M, Kulkarni B and Kumar A: Dorsal spinal epidural cavernous hemangioma. J Craniovertebr Junction Spine 1: 122-125, 2010.

11. Saracen A and Kotwica Z: Thoracic spinal epidural cavernous haemangioma with an acute onset: Case report and the review of the literature. Clin Neurol Neurosurg 115: 799-801, 2013.

12. Sharma MS, Borkar SA, Kumar A, Sharma MC, Sharma BS and Mahapatra AK: Thoracic extraosseous, epidural, cavernous hemangioma: Case report and review of literature. J Neurosci Rural Pract 4: 309-312, 2013.

13. Bayri Y, Ekşi MŞ, Yalçınkaya Koç D and Konya D: Spinal epidural cavernous angioma: Two case reports and review of the literature. Acta Orthop Traumatol Turc 49: 459-464, 2015.

14. Feng J, Xu YK, Li L, Yang RM, Ye XH, Zhang N, Yu T and Lin BQ: MRI diagnosis and preoperative evaluation for pure epidural cavernous hemangiomas. Neuroradiology 51: 741-747, 2009.

15. Zhong W, Huang S, Chen H, Sun H, Cai B, Liu Y and You C: Pure spinal epidural cavernous hemangioma. Acta Neurochir (Wien) 154: 739-745, 2012.

16. Khalatbari MR, Abbassioun K and Amirjmshidi A: Solitary spinal epidural cavernous angioma: Report of nine surgically treated cases and review of the literature. Eur Spine J 22: 542-547, 2013. 
17. Li TY, Xu YL, Yang J, Wang J and Wang GH: Primary spinal epidural cavernous hemangioma: Clinical features and surgical outcome in 14 cases. J Neurosurg Spine 22: 39-46, 2015.

18. Chiles BW III, Leonard MA, Choudhri HF and Cooper PR: Cervical spondylotic myelopathy: Patterns of neurological deficit and recovery after anterior cervical decompression. Neurosurgery 44: 762-770, 1999.

19. Labauge P, Bouly S, Parker F, Gallas S, Emery E, Loiseau H, Lejeune JP, Lonjon M, Proust F, Boetto S, et al: Outcome in 53 patients with spinal cord cavernomas. Surg Neurol 70 176-181, 2008.

20. Barker FG III, Amin-Hanjani S, Butler WE, Lyons S, Ojemann RG, Chapman PH and Ogilvy CS: Temporal clustering of hemorrhages from untreated cavernous malformations of the central nervous system. Neurosurgery 49: 15-24, 2001.

21. Gao W, Qiao X, Ma S, Ma J, Dong X, Qin T and Fang Q: Contribution of skin trauma to infantile skin hemangioma. Med Hypotheses 76: 512-513, 2011.

22. Demir MK, Ozdemir H, Unlu E, Temizöz O and Genchellac H: Differential diagnosis of spinal epidural meningioma and hemangioma at MR imaging. Radiology 244: 933, 2007.

23. Uchida K, Yayama T, Nakajima H, Hirai T, Kobayashi S, Chen K, Guerrero AR and Baba H: Microsurgical resection of cavernous haemangioma around the thoracic neuroforamen: A case report. J Orthop Surg (Hong Kong) 18: 370-373, 2010.
24. Demachi H, Takashima T, Kadoya M, Suzuki M, Konishi H, Tomita K, Yonezawa $\mathrm{K}$ and Ubukata A: MR imaging of spinal neurinomas with pathological correlation. J Comput Assist Tomogr 14: 250-254, 1990.

25. Wu L, Yang T, Deng X, Yang C, Zhao L, Yao N, Fang J, Wang G, Yang J and Xu Y: Spinal extradural en plaque meningiomas: Clinical features and long-term outcomes of 12 cases. J Neurosurg Spine 21: 892-898, 2014.

26. Gelabert-González M and García-Allut A: Spinal extradural angiolipoma: Report of two cases and review of the literature. Eur Spine J 18: 324-335, 2009.

27. Caroli E, Acqui M, Trasimeni G, Di Stefano D and Ferrante L: A case of intraroot cauda equina cavernous angioma: Clinical considerations. Spinal Cord 45: 318-321, 2007.

28. Lee JW, Cho EY, Hong SH, Chung HW, Kim JH, Chang KH, Choi JY, Yeom JS and Kang HS: Spinal epidural hemangiomas: Various types of MR imaging features with histopathologic correlation. AJNR Am J Neuroradiol 28: 1242-1248, 2007.

29. Gencpinar P, Açıkbaş SC, Nur BG, Karaali K, Arslan M, Gurer EI, Duman O and Haspolat S: Epidural capillary hemangioma: A review of the literature. Clin Neurol Neurosurg 126: 99-102, 2014

30. Padovani R, Acciarri N, Giulioni M, Pantieri R and Foschini MP Cavernous angiomas of the spinal district: Surgical treatment of 11 patients. Eur Spine J 6: 298-303, 1997. 